\title{
A Public Health Perspective on the Stigmatization of Mental Illnesses
}

\author{
Heather Stuart, $\mathrm{PhD},{ }^{1}$ \\ Julio Arboleda-Flórez, MD, FRCPC, $\mathrm{PhD}^{1}$
}

\begin{abstract}
Mental illness stigma occurs when individuals are devalued or treated unfairly by others because of their mental health condition. The stigmatization of people with mental illnesses has been recognized by international agencies such as the World Health Organization and the World Psychiatric Association as an important public health and human rights problem. This paper reviews the origins of mental illness stigma and examines population-based research that describes public perceptions of people with a mental illness; experiences of stigma by people who have a mental illness; and mental health literacy. It shows that, in spite of increasing public knowledge about mental illnesses, their causes, and their treatments, people who have a mental illness and their family members continue to be stigmatized in ways that limit their civic participation and human rights. The paper closes with recommendations for evidence-based anti-stigma programming that is focused on the needs and priorities of people who have experienced a mental illness, argues for more comprehensive epidemiologic data describing the frequency and personal impact of stigma experiences and recommends that public health agencies view stigma reduction as part of their global mental health mandate.
\end{abstract}

Key Words: Stigma, stigmatization, mental illness stigma, mental health stigma

Reccomended Citation: Stuart H, Arboleda-Flórez J. A public health perspective on the stigmatization of mental illnesses. Public Health Reviews. 2012;34: Epub ahead of print.

\section{INTRODUCTION}

"In most parts of the world psychiatry is not recognized as a medical discipline equal to others. Its practitioners are often considered to be charlatans unable to provide real help and likely to do evil things.

\footnotetext{
${ }^{1}$ Queen's University, Kingston, Ontario, Canada.

Corresponding Author Contact Information: Heather Stuart at heather.stuart@queensu.ca; Professor and Bell Canada Mental Illness and Anti-stigma Research Chair, Queen's University, Kingston, Ontario, Canada, K7L 3N6.
} 
People suffering from mental illness are not seen as people requiring help, but as weaklings, evil doers or simulants. Their human rights are often not respected, and the care they receive is usually sub-optimal"

Norman Sartorius ${ }^{1(p .186)}$

In this chapter, the term 'stigmatization' or 'stigma' is used to describe a complex social process with a number of interlocking components, including cognitive and psychological processes, such as labeling and stereotyping; socio-cultural processes resulting in separation, status loss, and discrimination; and broad structural processes based on the exercise of social, economic, and political power; all of which work in concert to systematically disadvantage and limit the life chances of people who have a mental illness. ${ }^{2}$ The World Health Organization describes stigma as the "hidden burden" of mental illness because it is difficult to quantify and, in many cases, remains concealed and unreported. ${ }^{3}$

This paper reviews the origins of mental illness stigma and examines population-based research that describes public perceptions of people with a mental illness; experiences of stigma by people who have a mental illness; and mental health literacy. It shows that, in spite of increasing public knowledge about mental illnesses, their causes, and their treatments, people who have a mental illness and their family members continue to be stigmatized in ways that limit their civic participation and human rights. The paper closes with recommendations for evidence-based anti-stigma programming that is focused on the needs and priorities of people who are stigmatized, argues for more comprehensive epidemiologic data describing the frequency and impact of stigma experiences and recommends that public health agencies incorporate stigma reduction efforts as part of their global mental health mandate.

\section{DISCUSSION}

The literature dealing with the stigmatization of mental illnesses is vast, dating back to the middle of the last century and cannot be summarized in detail within the scope of this review. Therefore, the following section provides a general discussion of the origins and nature of mental illness related stigma with an eye to considering population-based work that could broadly inform public health programming and population surveillance. It is meant to be a high level overview to raise awareness of the public health importance of mental illness related stigma. An unavoidable limitation of this approach is a lack of detail concerning specific findings reported in the literature. 


\section{The Origins and Nature of Mental Illness Related Stigma}

The public health importance of mental illnesses is undeniable. In 1990, five of the top ten leading causes of disability worldwide were mental disorders, accounting for 15 percent of the total burden of disease and 22 percent of the total years lived with a disability. ${ }^{4}$

Contemporary disability discourse, such as that reflected in the United Nations Convention on the Rights of Persons with Disabilities, recognizes that social environments, not an individual's impairments, produce disability through discrimination, social oppression, and social inequity. People are disabled because their environments fail to make appropriate accommodations to allow their full and effective participation. ${ }^{5}$

People with mental illnesses are among the most stigmatized of all groups. Many report that the experience of stigma is more long lasting, life limiting, and disabling than the illness itself. ${ }^{6}$ In addition, as the opening quote illustrates, stigma has many faces. It not only affects the person with the mental illness, but it also reverberates through social and professional support networks to affect family, friends, mental health care providers, mental health delivery systems, and mental health research. As there can be no health without mental health, the stigmatization of mental illnesses stands out as one of our greatest public health challenges. ${ }^{7}$

The stigmatization of people with mental illnesses has deep historical roots. Early Greek writings, for example, linked mental illnesses with shame, loss of face, and humiliation - all of which continue to this day. The earliest asylums, founded in Spain and Egypt (in the 1400's), were originally erected to protect people with a mental illness from being bullied and brutalized. Similarly, the early asylum movement of the late 1800's in Europe and North America was based on a humanistic ideal (popularized by Pinel and Tuke), that the mad were not beasts, but human beings who should be treated with compassion. These asylums were founded on the idea of moral treatment. This was a form of compassionate psychological intervention that involved the re-education of the patient within a proper moral atmosphere. Moral therapy stood in stark contrast to the medical therapeutics of the day which included bleeding, blistering, purges, emetics, opium, and liberal use of punishment and physical restraints. ${ }^{8}$ However, the therapeutic optimism and compassion that were the hallmarks of moral therapy were short lived, and while asylums were originally intended to be places of refuge, they soon degenerated into human warehouses where people with mental illnesses ('deviants') could be segregated from society, usually against their will. Despite wide recognition that such institutions are anti-therapeutic and promote human rights violations, they remain the preferred form of management for mental illness in most parts of the world today. ${ }^{9}$ 
By the early $19^{\text {th }}$ century, most physicians would have endorsed the idea that mental illnesses were a result of a hereditary dysfunction in the brain. Because heredity was considered to account for nine-tenths of all mental illnesses, early physicians did little to seek cures. Rather, an effort was made to identify and classify 'lunatics' by morphological stigmata such as pointed ears, stunted growth, or cranial abnormalities. In addition, mental illnesses were tied to other forms of degeneracy, which conferred a broader stigma of moral incapacity on all of its victims and made the prison-like conditions of the asylums seem more acceptable. Ideas of hereditary degeneracy were still popular until the First World War, fuelling the eugenics movement of the day. ${ }^{9}$

Public health concern for mental illnesses emerged following the Second World War when the first attempts were made to collect community-based epidemiologic data. Prior to 1948, there was no international statistical system capable of reporting mental disorders in untreated populations. Based on their experience with psychiatric casualties among soldiers during the war, the United States Army developed a comprehensive classification system that subsequently formed the basis for the first international classification of mental disorders (contained in ICD-6) published by the WHO. ${ }^{10}$ Studies published after this time used this system to publish the first community estimates of the prevalence of mental illnesses. ${ }^{11}$

The Stirling County Study (which sampled the general population in Atlantic Canada up until May 1, 1952) may have been the first community survey to use the full range of diagnostic types. Using a combination of diagnosis and degree of impairment, The Stirling County Study estimated that 20.7 percent of the population was in need of psychiatric treatment. ${ }^{12}$ The Midtown Manhattan Study in New York City, a close contemporary to the Stirling County Study, used a linear scale to describe level of functional impairment. In their first, 1954 wave, 14.3 percent of the general popualtion sample was identified as experiencing marked or severe symptoms, or was entirely incapacitated. ${ }^{13}$ These studies provided the first glimpses of the high and previously unrecognized burden associated with mental illnesses in untreated populations.

As community epidemiologic studies matured, it soon became apparent that there was a large gap between the proportion of people who met the study criteria for an illness (and, therefore were thought to be in need of treatment) and the proportion that actually received treatment. Table 1 summarizes results from Kohn et al. ${ }^{14}$ who reviewed 37 community-based studies published after 1980 that used standardized diagnostic criteria and presented the proportion of respondents receiving mental health treatment. The median proportion of those who met the criteria for a diagnosis but 
who were not receiving treatment for their condition ranged from 32 percent to 78 percent. More recent data from the WHO's Mental Health Consortium Surveys (reported in 2005) showed that 30 percent to 50 percent of those in developed countries who meet the criteria for a mental disorder had not received treatment in the year prior to the survey. In developing countries unmet need was 76 percent to 85 percent. ${ }^{15}$

\section{Table 1}

Summary of Studies Reporting Unmet Need

\begin{tabular}{l|l}
\hline \multicolumn{1}{c|}{ Disorder Category } & \multicolumn{1}{c}{$\begin{array}{c}\text { Median proportion who met the criteria } \\
\text { and were not receiving treatment }\end{array}$} \\
\hline Schizophrenia and non-affective psychosis & $32.2 \%$ \\
\hline Bipolar Disorder & $50.2 \%$ \\
\hline Panic Disorder & $55.9 \%$ \\
\hline Major Depression and Dysthymia & $56.3 \%$ \\
\hline Generalized Anxiety Disorder & $57.5 \%$ \\
\hline Obsessive Compulsive Disorder & $59.5 \%$ \\
\hline Alcohol Abuse and Dependence & $78.1 \%$ \\
\hline
\end{tabular}

Source: Kohn et al. ${ }^{14}$

Numerous reasons could explain the high unmet need including failing to seek treatment because the problem is not acknowledged, perceptions that psychiatric treatments are harmful or ineffective, believing that the problem will resolve on its own, or wanting to deal with the problem on one's own. In addition, barriers to care such as financial barriers or lack of services may be important factors. However, the large treatment gap persists even in countries with good mental health literacy and access to care. For example, in Canada, where health care is universally accessible and the population has relatively high mental health literacy, Kohn et al. ${ }^{14}$ still report large gaps ranging between 44 percent for major depression to 84 percent for substance dependence. An alternate explanation is that people avoid seeking treatment because of the significant social consequences associated with becoming a 'mental patient' ${ }^{11}$ Corrigan ${ }^{16}$ has referred to this as 'label avoidance' and notes that many people will avoid treatment at all costs in order to evade the stigma that flows from being given a psychiatric diagnosis. If disability is to be reduced, the treatment gap must be reduced, and if stigma is an important factor, then stigma reduction must become a regular part of public health. 
In the next sections we discuss the burden of stigma from three perspectives that have particular relevance for public health programming: first, the prevalence of stigmatizing attitudes held by members of the public; second, because public attitudes (even negative ones) may not result in discriminatory behaviours, the prevalence of stigmatizing experiences reported by people who have a mental illness will be examined; and third, because stigma is often considered to be a result of ignorance and misinformation, mental health literacy, specifically the relationship between mental health literacy and stigmatizing attitudes will be examined.

\section{Contemporary Public Perceptions of People with a Mental Illness}

Much is known about the epidemiology of public stigma from recent studies of representative community samples. For example, between 1990 and 2004, Angermeyer and Deitrich identified 33 national, and 29 local population-based attitude surveys published in the English language literature. ${ }^{17}$ Depression was most often featured (in 31 studies), followed by schizophrenia (29 studies), alcoholism (8 studies), anxiety disorders (7 studies), dementia (6 studies), and drug addiction (4 studies). Although the study methods were not directly comparable, there appeared to be considerable variation in public perceptions across cultures and diagnostic categories. Cultural differences were noted in the proportion of people who were ready to acknowledge patients' social competence and civil rights, in common stereotype endorsement, and in preferences for social distance. In addition, people with depression often garnered greater sympathy and less social rejection than those with schizophrenia or substance use disorders.

Pescosolido and colleagues directly compared public attitudes to depression and schizophrenia in representative samples from Bulgaria, Germany, Hungary, Iceland, and Spain. ${ }^{18}$ They confirmed that the percentage of respondents who endorsed stigmatizing views differed significantly across countries and across disorder categories. The post-communist countries, with a lower level of per capita gross domestic product, had higher levels of rejection compared to the more economically advanced nations. Respondents reported greater rejection when rating a vignette that described someone with schizophrenia compared to someone with depression. The lowest levels of rejection were reported in relation to work, with higher levels of rejection associated with community and family settings.

One of the central stereotypes held about people with a mental illness that contributes to social intolerance and social exclusion is that they are violent and unpredictable. Endorsement of this stereotype has been associated with public preferences for coercive treatment, legislative 
solutions, and acceptance of social inequities, injustices, and human rights violations. For example, a random sample of 1,500 Americans responding to the General Social Survey (an annual survey that collects data on demographics and attitudes of US residents) were asked to estimate the likelihood that someone with a mental illness would be a danger to others, and to indicate whether they supported involuntary hospitalization for that person. The results showed that the American public clearly differentiated between diagnostic groups, though they greatly exaggerated risk in every case. Approximately 20 percent of those who were labeled as troubled (likely understood as referring to a variety of less serious emotional problems) were estimated to be dangerous to others, compared to approximately 30 percent of those who were depressed, 60 percent of those who had schizophrenia, and 70-80 percent of those with substance dependence (alcohol or drug). Between 80-100 percent of respondents (depending on the diagnostic group) favoured involuntary hospitalization for that disorder when they thought that violence was an issue. ${ }^{19}$

Though longitudinal studies are unavailable, there is some evidence that stereotypes of violence and unpredictability have increased over time, particularly with reference to people with a psychotic illness such as schizophrenia. Using comparable methods and measures Phelan and colleagues compared public attitudes to mental illness in representative samples of Americans in 1950 and 1996. ${ }^{20}$ They found that conceptions of what constituted a mental illness had broadened between the surveys and were less based on clinical diagnostic categories. In 1950, the majority of respondents identified psychosis (40.7\%) and anxiety/depression $(48.7 \%)$ when asked to define mental illness. Social deviance $(7.1 \%)$, mental deficiency/cognitive impairment (6.5\%), and other non-psychotic disorders (7.1\%) were identified relatively infrequently. By 1996, there was a large increase in the proportion of respondents who included non-specific social deviance and behavioural problems as part of their definition: psychosis (34.9\%), anxiety/depression (34.3\%), social deviance (15.5\%), mental deficiency/cognitive impairment (13.8\%) and other non-psychotic disorders $(20.1 \%)$. The proportion of respondents mentioning violence in their descriptions also increased from 12.7 percent in 1950 to 31.0 percent in 1996, but this was concentrated among respondents who included psychoses in their definitions.

\section{Public Perception of Family Members}

In Goffman's (1963) seminal work on stigma, he identified 'courtesy stigma' as the stigma that family members experience because of their close 
association with the stigmatized individual. ${ }^{21}$ In most parts of the world, family members provide the bulk of community care for people who have a mental illness. Historically, families have been blamed for creating mental illnesses (through hereditary taints or poor parenting) or for harboring dangerous individuals in their midst. Blaming has been a major tenet of $20^{\text {th }}$ century conceptions of mental illness. For example, an enduring attribution has been that mental illnesses are within the individual's control; that someone could snap out of it if they only tried harder; if they pulled up their boot straps. When the belief is that someone with a mental illness can exert personal control over their symptoms and functioning, blame and castigation are typical reactions, often leading to overt rejection and punishment. ${ }^{22}$

In a recent review of the literature, Larson and Corrigan ${ }^{23}$ found that 25 percent to 50 percent of family members reported trying to hide their relationship in order to avoid bringing shame to the family; 20 percent to 30 percent reported that relationships with extended family members and friends were strained, and 20 percent to 30 percent reported lowered selfesteem because they had a relative with a mental illness. Thus, they define 'family stigma' in terms of a triumvirate of blame, shame, and contamination.

Despite the impact that stigma by association has on family members, conventional search terms and citation trails yielded only one large population study of public perceptions of family members. Corrigan and colleague ${ }^{24}$ studied a national sample of 968 Americans who were members of a research panel. Respondents read vignettes that were randomly varied across three health conditions (schizophrenia, drug dependence, and emphysema) and family roles (parent, child, sibling, and spouse). Seven items pertained to attributions about the individual with the health condition, and seven pertained to the family member. Each item was scaled on a 7-point agreement scale. Somewhat surprisingly, family member stigma associated with a relative with schizophrenia or emphysema was not highly endorsed (with average scores of 2.4 for schizophrenia and 2.4 for emphysema, compared to 2.8 for drug dependence). However, parents or spouses of a relative who was dependent on drugs (most likely understood as illicit street drugs) were viewed as more blameworthy for the onset and for relapses, were more likely to be viewed as shameful, and would be avoided socially.

\section{Personal Stigma Experiences}

Results of studies of public stigma show that it is ubiquitous but plays out in socially and culturally specific ways. They also demonstrate that the public makes important distinctions by diagnostic group in the way that they stereotype, and perhaps also in their actions towards members of these groups. A lack of population-based research describing personal experiences 
with stigma, however, makes the prevalence of discrimination difficult to assess. It also means that public health (and other) programming has been undertaken largely without reference to the priorities and needs of those who are stigmatized. The lack of population data on stigma experiences stands out as a significant public health gap. Not only is this information important for quantifying the hidden burden of mental illnesses and for targeting programs to areas where they are most needed, changes in the frequency and/or intensity of stigma experiences will be an important means of evaluating the success of public health interventions designed to improve social inclusion for people with a mental illness.

Wahl ${ }^{25}$ was the first to conduct a large-scale national survey of people who experience stigma. Volunteers were recruited through the National Alliance for the Mentally Ill in the United States. Over one thousand $(\mathrm{n}=1,388)$ completed a survey questionnaire and 100 were subsequently interviewed. Almost three quarters $(74 \%)$ had avoided disclosing their mental illness to people outside of their immediate family. The majority $(71 \%)$ reported that they had denied having had a mental illness on written applications for fear that this information would be used to discriminate against them. Almost a third (31\%) indicated that they had been turned down for a job they were qualified to do once they disclosed they had a mental illness. Approximately one in ten said their stigma experiences had made them reluctant to seek professional help because they did not want to be told that they were lacking in character, weak-willed, or that they would have to lower their life goals and expectations. Many had avoided social situations so as not to be found out.

In 2009, the International Study of Discrimination and Stigma Outcomes (INDIGO) network ${ }^{26}$ surveyed 25 volunteers with schizophrenia who were receiving outpatient care in each of 27 countries $(n=732)$. Almost half (47\%) reported that they had experienced discrimination. The most common areas of discrimination were in making or keeping friends $(47 \%)$, discrimination from relatives (43\%), finding a job (29\%), keeping a job (29\%), and intimate sexual relationships (27\%). The majority (64\%) reported that they expected to be discriminated against and 72 percent reported that they felt the need to conceal their diagnosis.

In 2010, Brohan and colleagues ${ }^{27}$ surveyed a systematically selected sample of members of the Global Alliance of Mental Illness Advocacy Networks. The analysis was based on 1,229 returned postal surveys from 21 sites across 14 countries (74\% response). All respondents had a selfreported diagnosis of schizophrenia or other psychotic illness. The investigators assessed experiences with alienation; the extent to which individuals endorsed commonly held stereotypes; experiences with discrimination; 
level of social withdrawal; and the extent to which they considered the public held negative attitudes towards mental health service users. Based on aggregated sub-scale scores for each domain, 47 percent scored in the moderate to strong range of the alienation sub-scale; 48 percent on the discrimination experiences sub-scale; 45 percent on the social withdrawal sub-scale; and 28 percent on the stereotype endorsement scale (meaning that they agreed with and thought that common stereotypes applied to themselves). In addition, the majority (69\%) considered that the public held negative attitudes towards mental health service users.

Finally, in 2012, Stuart et al. ${ }^{9}$ report preliminary data from a representative sample of 10,000 Canadians that was undertaken by Statistics Canada (Canada's national reporting organization) in conjunction with the Mental Health Commission of Canada's Opening Minds anti-stigma initiative. Of the seven percent of the sample that reported having been treated for a mental illness in the year prior to the survey, 18 percent reported that stigma had impacted their housing situation, 25 percent their financial situation, 28 percent their work or school life, 30 percent their romantic life, and 32 percent their family relationships.

\section{Mental Health Literacy}

Mental health literacy refers to knowledge of mental illnesses and their treatment that aids in their recognition, management, and prevention. It includes the ability to recognize specific disorders, knowledge and beliefs about risk factors and causes, knowledge and beliefs about interventions, and knowledge and beliefs about professional help. ${ }^{28} \mathrm{~A}$ recent review of the English and German language literature conducted by the World Psychiatric Association's Task Force on the Destigmatization of Psychiatry and Psychiatrists found that public opinions about psychiatric treatments are often negative and ill-informed. For example, psychotherapies were usually preferred over psychotropic medications, but with exaggerated effectiveness even for conditions such as schizophrenia where scientific evidence calls for psychopharmacological interventions. Psychotropic medications were misperceived as being addictive, a sedative without cure, an invasion of identity, merely drugging patients, and ineffective in preventing relapse. The status of psychiatry as a discipline among the public (and among medical colleagues) was also low. The duration of psychiatric training was often under-estimated, it was not always clear that psychiatrists were medical doctors, and they were perceived as relying too much on medications (pill pushers). Dominant stereotypes about psychiatrists portrayed them as dangerous, manipulative, and exploitative..$^{29}$ 
A core assumption of many public education programs has been that greater mental health literacy_particularly information that emphasizes biological causes - will combat prejudice and discrimination. Thus, much effort has gone into teaching the general public how to recognize symptoms of common disorders (such as depression), available treatments, and to highlight the fact that mental illnesses are illnesses like any other, meaning they have biogenetic causes. Haslam and colleagues ${ }^{30}$ reviewed the peerreviewed literature espousing a biogenetic (disease like any other) paradigm. They summarize 37 studies, mostly cross-sectional, from 17 countries, spanning 50 years. With few exceptions, members of the public who adopted a biologic view of mental illnesses were more fearful and distancing. Furthermore, providing a diagnostic label, as opposed to describing it in a vignette, increased the belief in biogenic causes and seriousness, and produced a more pessimistic view about the possibility of recovery. Thus, it seems that when the disease model is applied to mental illnesses, the assumption is made that the individual is more dangerous, unpredictable, and incapable of judgment, reason, and, therefore, autonomy.

Several studies have used repeat surveys to examine the relationship between population changes in knowledge about mental disorders and prejudicial attitudes. Angermeyer, Holzinger, and Matschinger ${ }^{31}$ examined data from two population-based surveys conducted in the eastern part of Germany in 1993 and 2001. In 1993, 49 percent of the sample recognized that schizophrenia was a brain disease and this rose significantly to 67 percent in 2001. Similarly, the percentage of respondents recommending psychotropic medications to treat schizophrenia rose from 36 percent to 51 percent and the percentage recommending treatment from a psychiatrist increased from 77 percent to 82 percent. At the same time, the amount of social distance desired by the public toward someone with schizophrenia remained unchanged in most social relationships (tenant, coworker, neighbor, child care, in-law) or rose in the case of having someone with schizophrenia in the same social circle or recommended for a job. In 1993, 49 percent said they would not recommend someone with schizophrenia for a job, rising to 60 percent in 2001. These results confirmed findings from an earlier series of surveys (conducted in 1990 and 2001) where Angermeyer and Matschinger reported greater sympathy, but no changes in expressions of fear or desire for social distance from people with depression. ${ }^{32}$

More recently, Pescosolido et al. ${ }^{33}$ assessed changes in Americans perceptions using the 1996 and 2006 US based General Social Surveys that contained vignette descriptions of individuals who met clinical criteria for major mental illnesses (schizophrenia, major depression, and alcohol 
dependence). The literacy indicators improved, but the stigma indicators did not. For example, this study showed that in 1996, 54 percent of the American public attributed major depression to neurobiological causes, increasing to 67 percent in 2006. Similarly, those attributing a neurobiological cause to schizophrenia increased from 76 percent to 86 percent and for alcohol dependence, this increased from 38 percent to 47 percent. Statistically significant improvements occurred in the percentage of respondents that endorsed treatment by a physician, a specialist, and the need for prescription medication. With respect to social distance, however, the majority of respondents in both samples expressed an unwillingness to work or socialize with someone with schizophrenia, depression, or alcohol dependence. For example, in 1996, 34 percent of the sample would be unwilling to have someone with schizophrenia as a neighbor. This rose to 45 percent in 2006 reflecting a statistically significant change. Items remained steady and were endorsed by 35 percent to 69 percent of the sample indicating high levels of social intolerance. With respect to depression, one item did not change and the remaining items decreased by two to five percent with none of these reaching statistical significance. For alcohol dependence, one item showed a statisticallly significant increase in social distance and the remaining items were relatively unchanged. In 2006, levels of social distance for depression ranged from 20 percent to 53 percent, for schizophrenia from 35 percent to 69 percent, and for alchol dependence from 36 percent to 79 percent. Sixty percent thought that someone with schiozphrenia would be violent toward others (up from 54\% in 1996), a third of the sample thought that someone with depression would be violent toward others (with no change over time) and two thirds thought that someone with alcohol dependence would be violent toward others (with no change over time). These results challenge public health approaches that proliferate a neurobiological understanding of mental illnesses as a way of reducing stigma.

Despite the fact that literacy may be unrelated or inversely related to stigma in the general public, Jorm and colleagues ${ }^{34}$ have argued that improved mental health literacy is still important because it may improve help-seeking and treatment adherence among people who have mental health problems. They examined the relationship of public beliefs about the efficacy of treatments with their actual use over six months by people with symptoms of anxiety or depression. With the exception of antidepressant use (where beliefs predicted use), they found major discrepancies between the baseline ranking of helpful interventions and the frequency with which respondents subsequently used them. For example, 93 percent of the sample gave counseling the highest ranking, whereas only 15 percent had used it in 
the six months following (with the result that it ranked $17^{\text {th }}$ amongst actual treatments used). The most consistent predictors of intervention use across all interventions were past history of treatment, severity of current symptoms, belief in a partiular intervention, and female gender (particularly for lifestyle changes).

These studies challenge the assumption that improved literacy, and particularly greater understanding of neurobiological causes, would help people understand that mental illnesses are illnesses like any other and that their symptoms denote 'real' illnesses, rather than bad behaviours. They also cast doubt on the effectiveness of attempting to change public perceptions of treatments on the assumption that they will lead to greater help-seeking or treatment adherence and argue for a more targeted approach to literacy education.

\section{RECOMMENDATIONS}

As the hidden burden of stigma has become increasingly recognized, numerous anti-stigma efforts have emerged at local, national, and international levels. However, many of these programs rest on a theory of change that is not evidence-based. Promoting the message that mental illnesses are 'illnesses like any other' has not reduced social distance, and in some studies it has increased it. Despite being more knowledgeable about mental illnesses, the public is as socially distancing as ever. People who have a mental illness and their family members continue to be stigmatized in ways that significantly limit their civic and human rights. ${ }^{35}$ Haslam and colleagues have argued that anti-discrimination work in the field of mental health has been overly focused on etiology in ways that have not occurred in other areas. For example, in challenging discrimination by people who use wheelchairs, the causes of their impairments have not been relevant. What was relevant was their right to be included in social and economic life. ${ }^{30}$

In Paradigms Lost, Stuart, Arboleda-Flórez, and Sartorius ${ }^{9}$ argue that it is time to adopt a new paradigm to guide anti-stigma programming. The point of departure should be the day-to-day experiences of people who have a mental illness and their family members so that these set the priorities for local action. Further, they suggest that additional surveys of public attitudes will not help policy-makers or programmers understand the impact of stigma on people who have experienced a mental illness or meaningfully identify their priorities for change. Similarly, they argue that changes in public attitudes should not be used as the yardstick of success 
for anti-stigma efforts because they correlate poorly with discriminating behaviours and do little to focus attention on social structures that create and maintain social inequities. Instead, public health advocacy activities designed to remove social, organizational, and other barriers to social inclusion are needed. In addition, focused interventions that break down barriers using social contact with people who have recovered from a mental illness are recommended. Indeed, contact-based education (which occurs when trained speakers who have recovered from a mental illness deliver in class training and workshops) has emerged as one of the most promising anti-stigma practices to date and has been applied successfully in schoolbased programs in both developed and developing countries. Public health practitioners who have regular access to youth in school based settings could be instrumental in fostering opportunities for contact-based education pertaining to mental illnesses as part of their regular prevention and promotion activities.

Population-based studies of personal stigma experiences are lacking. Indeed, this stands out as one of the least developed areas of the epidemiologic study of stigma. Achieving a better understanding of peoples' lived experiences with mental illnesses is, therefore, recommended. Not only will this provide a finer grained understanding of the multiple points and intersections where stigma impinges on social and psychological health, it will help focus anti-stigma activities in areas where they can make changes that are important in the day-to-day lives of people who bear the brunt of stigma and provide a means of evaluating changes over time. Therefore, it is further recommended that public health agencies include measures of personal stigma as part of their routine data gathering and reporting so that stigma programmers can use this information to set priorities for mental health promotion and prevention and evaluate change.

Finally, public health agencies must recognize that stigma is a major social determinant of mental health and mental illness. As such, stigma reduction must be included as part of a broad chronic disease mandate. This means that public health agencies must support enhanced population survillance concering the frequency and impact of stigma experiences, promote epidemiolgical research into the determinants and consequences of stigma and factors that may promote stigma resillience, identify areas where promotion and prevention strategies may reduce stigma, aid in the education of the public and health professions concerning this hidden burden of mental illness, and advocate for greater integration of stigma reduction strategies within the broad public health mandate with the ultimate goal of reducing social inequities experienced by people with a mental illness. 


\section{SUMMARY}

This paper has reviewed the origins of mental illness stigma and examined population-based research that describes public perceptions of people with a mental illness; experiences of stigma by people who have a mental illness; and mental health literacy. It shows that, in spite of increasing public knowledge about mental illnesses, their causes, and their treatments, people who have a mental illness and their family members continue to be stigmatized in ways that limit their civic and human rights. The paper closes with recommendations for evidence-based anti-stigma programming that focuses on the needs and priorities of people who are stigmatized and argues for the need for more comprehensive epidemiologic data describing the frequency and impact of stigma from the perspective of those who have been stigmatized. It makes the point that stigma is a global public health problem and, as such, public health agencies must incoporate stigma reduction as part of their chronic disease mandate.

About the Authors: Dr. Heather Stuart, MA (Sociology), PhD (Epidemiology) has been researching stigma for almost 15 years and is the co-founder and current chair of the Scientific Section on Stigma and Mental Health and an Honorary member of the World Psychaitric Association. She is also the inaugural Chair holder of the recently established Bell Canada Mental Health and Anti-stigma Research Chair at Queen's University, in Kingston Ontario. Dr. Stuart is a full Professior in the Department of Community Health and Epidemiology at Queen's University, with cross appointments to the Department of Pschiatry and School of Rehabiliation Therapy. She is also the Senior Consultant for the Mental Health Commission of Canada's Opening Minds Anti-stigma initiative.

Dr. Julio Arboleda-Flórez, MD, FRCPC, DABFP, PhD (Epidemiology) is Emeritus Professor at Queen's University in Psychiatry and Community Health and Epidemiology. He is the immediate Past-Head of the Department of Psychiatry at Queen's. Dr. Arboleda-Flórez is a leading authority on legal psychiatry and human rights. He is the Honorary Chair of the Forensic Section and a longstanding member of the Ethics Committee of the World Psychiatric Association. He has extensive experience in anti-stigma work and was Director of the Canadian Pilot site of the Open-the-Doors anti-stigma initiative of the World Psychiatric Association. He has contributed numerous publications including several books in the area.

Conflicts of Interest: None declared. 


\section{REFERENCES}

1. Sartorius N. Fighting for Mental Health: A Personal View. Cambridge: Cambridge University Press; 2002.

2. Link BG, Phelan JC. Conceptualizing stigma. Annu Rev Sociol. 2001;27:36385.

3. World Health Organizaton. The 'undefined and hidden' burden of mental health problems. Fact Sheet No. 218. WHO; 2001. Available from URL: https:// apps.who.int/inf-fs/en/fact218.html (Accessed 31 August 2012).

4. Murray CJL, Lopez AD. The Global Burden of Disease. Geneva: World Health Organization; 1996.

5. United Nations General Assembly. Convention on the Rights of Persons with Disabilities (CRPD). Geneva: UN; 2006.

6. Angermeyer MC, Schulze B, Dietrich S. Couresy Stigma--a focus group study of relatives of schizophrenia patients. Soc Psychiatry Psychiatr Epidemiol. 2003;38:593-602.

7. World Health Organization. Stop exclusion: dare to care. Geneva: WHO; 2001.

8. Stuart H, Arboleda-Flórez J, Sartorius N. Paradigms Lost. Fighting Stigma and the Lessons Learned Oxford: Oxford University Press; 2012.

9. Shilkret R. Moral treatment. In: Weiner IB, Craighead WE, (editors). Corsini Encyclopedia of Psychology. Published Online 30 January 2010. Available from URL: http://onlinelibrary.wiley.com.proxy.queensu.ca/doi/10.1002/ 9780470479216.corpsy0558/full (Accessed 5 January 2013).

10. Kramer ME. The history of the international classification of diseases. In: Mezzich JE, Jorge MR, Salloum IM, (editors). Psychiatric Epidemiology: Assessment Concepts and Methods. Baltimore, MD: The Johns Hopkins University Press; 1994. p.81-97.

11. Dohrenwend BP, Dohrenwend BS. Perspectives on the past and future of psychiatric epidemiology. The 1981 Rema Lapouse Lecture. Am J Public Health. 1982;72:1271-9.

12. Murphy JM. The Stirling County study. In: Weissman MM, Kyers JK, Ross CE, (editors). Community Surveys of Psychiatric Disorders. New Brunswick, NJ: Rutgers University Press; 1986. p.133-53.

13. Srole L, Fischer AK. The Midtown Manhatan longitudinal study: aging, generations, and genders. In: Weissman MM, Myers JK, Ross CE, (editors). Community Surveys of Psychiatric Disorders. New Brunswick, NJ: Rutgers University Press; 1986. p.77-108.

14. Kohn R, Saxena S, Levav I, Saraceno B. The treatment gap in mental health care. Bull World Health Organ. 2004;82:858-66.

15. The WHO World Mental Health Survey Consortium. Prevalence, severity, and unmet need for treatment of mental disorders in the World Health Organization World Mental Health Surveys. JAMA. 2004;291:2581-90.

16. Corrigan PW. How clinical diagnosis might exacerbate the stigma of mental illness. Soc Work. 2007;52:31-9. 
17. Angermeyer MC, Deitrich S. Public beliefs about and attitudes towards people with mental illness: a review of population studies. Acta Psychiatr Scand. 2006;113:163-79.

18. Pescosolido B, Olafsdottir S, Martin J, Long J. Cross-cultural aspects of the stigma of mental illness. In: Arboleda-Flórez J, Sartorius N, (editors). Understanding the Stigma of Mental Illness. Theory and Interventions. Chichester: John Wiley \& Sons; 2008. p.19-35.

19. Pescosolido B, Monahan J, Link B, Stueve A, Kikuzawa S. The public's view of the competence, dangerousness, and need for legal coercion of persons with mental health problems. Am J Public Health. 1999;89:1339-45.

20. Phelan JC, Link BG, Stueve A, Pescosolido BA. Public conceptions of mental illness in 1950 and 1996: what is mental illness and is it to be feared? J Health Soc Behav. 2000;41:188-207.

21. Goffman E. Stigma: Notes on the Management of Spoiled Identity. Englewood Cliffs, NJ: Prentice-Hall; 1963.

22. Hindshaw SP. The stigmatization of mental illness in children and parents: developmental issues, family concerns, and research needs. J Child Psychol Psychiatry. 2005;46:714-34.

23. Larson JE, Corrigan P. The stigma of families with mental illness. Acad Psychiatry. 2008;32:87-91.

24. Corrigan PW, Watson AC, Miller FE. Blame, shame, and contamination: the impact of mental illness and drug dependence stigma on family members. J Fam Psychol. 2006;20:239-46.

25. Wahl OF. Telling is Risky Business. Mental Health Consumers Confront Stigma New Brunswick, NJ: Rutgers University Press; 1999.

26. Thornicroft G, Brohan E, Rose D, Sartorius N, Leese M, INDIGO Study Group. Global pattern of experienced and anticipated discrimination against people with schizophrenia: a cross sectional survey. Lancet. 2009;373:408-15.

27. Brohan E, Elgie R, Sartorius N, Thornicroft G, GAMIAN-Europe Study Group. Self-stigma, empowerment and perceived discrimination among people with schizophrenia in 14 European countries: the GAMIAN-Europe study. Schizophr Res. 2010;122:232-8.

28. Jorm AF. Mental health literacy. Public knowledge and beliefs about mental disorders. Br J Psychiatry. 2000;177:396-401.

29. Sartorius N, Gaebel W, Cleveland HR, Stuart H, Akiyama T, Arboleda-Flórez J, et al. WPA guidance on how to combat stigmatization of psychiatry and psychiatrists. World Psychiatry. 2010;9:131-44.

30. Read J, Haslam R, Sayce L, Davies E. Prejudice and schizophrenia: a review of the 'mental illness is an illness like any other' approach. Acta Psychiatr Scand. 2006;114:303-18.

31. Angermeyer MC, Holzinger A, Matschinger H. Mental health literacy and attitude towards people with mental illness: a trend analysis based on population surveys in the eastern part of Germany. Eur Psychiatry. 2009;24: 225-32. 
32. Angermeyer MC, Matschinger H. Public attitudes to people with depression: have there been any changes over the last decade? J Affect Disord. 2004;83: 177-82.

33. Pescosolido BA, Martin JK, Long JS, Medina TR, Phelan JC, Link BG. "A disease like any other?" A decade of change in public reactions to schizophrenia, depression, and alcohol dependence. Am J Psychiatry. 2010; 167:1321-30.

34. Jorm AF, Medway J, Christensen H, Korten AE, Jacomb PA, Rodgers B. Public beliefs about the helpfulness of interventions for depression: effects on actions taken when experiencing anxiety and depression symptoms. Aust $\mathrm{N}$ Z J Psychiatry. 2000;34:619-26.

35. Callard F, Sartorius N, Arboleda-Flórez J, Bartlett P, Helmchen H, Stuart H, et al. Mental Illness, Discrimination and the Law. Fighting for Social Justice. Chinchester: John Wiley \& Sons; 2012. 